Dialogos

\title{
Isang Reaksyon sa "Ang Demokratikong Sistema at ang mga Modelo ng Pamumuno sa Pilipinas"
}

Paolo A. Bolaños

K

inukundisyon ng nalalapit na eleksyon sa Mayo ang ating kolektibong pag-iisip bilang mamamayan ng Pilipinas. Bahagyang hinuhubog nito ang ating kilos at salita na syang kumakatawan sa ating pag-asa at mga pangarap para sa ating sarili at para sa ating bansa. Dahil nakatuon ang atensyon natin sa nalalapit na eleksyon at dahil hindi maiwasang pag-usapan ang mga pambansang isyu na kadalasa'y mga pambansang suliranin (tulad ng kurapsyon at kahirapan), nagkakaroon tayo ng natatangi at mas malawak na pag-mumuni-muni sa ating sosyoholikal at politikal na sitwasyon, na tila namang nambubuyo sa ating pakiramdam ng kabiguan. Talaga naman na ang panahon ng eleksyon ay parehong panahon ng pag-asa at kabiguan-kadalasa'y ang pangalawa ang nananatiling realidad ng mga Pilipino!

Sa aking pananaw, ang papel ng aking mabuting kaibigan na si Dr. F. P. A. Demeterio ay isang ekspresyon at inskripsyon ng pag-asa at pagkabigo. Ito'y napapanahon na talakayan sapagkat ang nilalaman nito ay seryosong diskurso sa istraktura at daynamiks ng sistemang politikal ng Pilipinas-isang topiko na di-maiiwasan sa panahon ngayon. Ngunit kinakailangan nating kilalanin ang substantibong kaibahan ng pagmumuni-muni ni Demeterio kumpara sa popular na pagsusuring politikal na araw-araw nating nakikita sa media. Kung ang popular na media ay naka-tuon sa "kompetisyon ng mga personalidad," kung saan ang inaasahang uri ng pamumuno ng isang kandidato lamang ang binibigyang hugis at imahen ang kanilang itinutudla, si Demeterio nama'y binigyang pansin at importansya ang istraktural na kondisyon ng ating sistemang politikal.

Sinubukang ungkatin ni Demeterio ang patolohikal (pathological) na kondisyon ng sistemang politikal ng ating bansa sa pamamagitan ng historyograpiya, maliban pa sa ibang istilo ng pamumunang sosyolohikal, partikular ang espesyal na historyograpiya na pina-usbong ng historyador na si Zeus Salazar. Sa pamamaraan ni Salazar, binalikan ni Demeterio ang mga sinaunang (pre-Spanish) modelo ng pamumuno na namana natin sa ating kasaysayan (ang datu, bagani, babaylan, at panday) upang iugnay ang mga ito sa

${ }^{1}$ This paper was read as a reaction to F. P. A. Demeterio's Don Francsico Ortigas, Sr. Professorial Chair Lecture held at De La Salle University, Manila, Philippines, 26 March 2010. [Editor's note]

(C) 2010 Paolo A. Bolaños

http://www.kritike.org/journal/issue 7/bolanos june2010.pdf

ISSN 1908-7330 
modelo ng demokrasya na ibinahagi naman ng Aleman na sosyologo na si Max Weber. Binuo muli ni Demeterio ang teorya ng demokrating pamumuno (o ang nabangit na Führerdemokratie) ni Weber upang subukang punahin o kaya'y bigyan ng napapanahong interpretasyon na sosoyolohikal at politikal, ang mga nabanggit ni Salazar na mga sinauna at katangi-tangi o "indigenous" na mga modelong pamumuno. Sa ganitong pamamaraan ng pagpuna, binibigyang-diin ni Demeterio ang historikal na basehan ng ating mga suliraning sosyolohikal at politikal, isang aspeto ng pambansang kondisyon na hindi masyadong binibigyang pansin ng media. Bukod sa basehang historikal, binigyan diin din ni Demeterio ang importansya ng paggamit ng teorya (tulad ng paggamit ng sulatin ni Weber), isa namang aspeto ng pamumunang sosyolohikal na hindi nakasanayang arukin ng karamihan ng ating mga sosyolohista. Hindi biro ang paggamit ng teorya at hindi maaring basta-basta gumamit ng kahit anong teorya. Kadalasan gumagamit tayo ng mga bagong salita na hango sa mga makabagong sistema ng diskursong akademiko (e.g., postmodernism, deconstruction, feminism, etc), samantalang lingid sa ating kaalaman ay hindi natin nagagamit nang wasto ang mga ito. Sa ibang salita, nakakalimutan nating ilagay sa kontekstong lokal ang paggamit natin ng teoryang banyaga. Gayunpaman, hindi ibig sabihin na ititigil natin ang paggamit ng teoryang banyaga; ngunit dapat nating isaalang-alang na kailangan ang sapat na kaalaman ng mga teoryang ito, sapagkat ang sapat na kaalaman ang kondisyon ng wastong kontekstuwalisasyon ng mga ito. Mahalagang mabatid natin ang kahalagahan ng pragmatikong gamit ng teorya-ito ay ginagamit na kasangkapang konseptuwal, upang maunawaan natin ang topiko ng ating pagsusuri sa sistemang literal o metaporikal.

Kung gayon, sa aking palagay, tumpak ang paggamit ni Demeterio ng mga konseptwal na haka-haka ni Weber-partikular ang mga konseptong pamumuno, tulad ng, tradisyunal, karismatiko, at legal-burukratiko—sapagkat ang mga ito nama'y ginamit na kasangkapang konseptuwal (conceptual tools). Ayon sa isa ring Aleman na pilosopo na si Theodor Adorno: mahalaga ang paggamit ng mga konsepto; dahil ang mga konsepto ang nagpapahintulot ng posibilidad ng pag-iisip o pagmumuni-muni sa ating materyal na kapaligiran. Ngunit, mabilis ding idinugtong ni Adorno na ang materyal na kapaligiran natin ang mas may higit na prayoridad at hindi dapat ito ibaba sa antas ng konsepto. Ibig sabihin, ang diskursong akademiko ay makikinabang nang lubusan sa paggamit ng mga konsepto o teorya, basta't maisamalay natin na ang mga kasangkapang konseptuwal na ito ay makakatulong para sa ating pagpapasya. Naniniwala ako na ito mismo ang konteksto ng paggamit ni Demeterio ng mga haka-haka ni Weber. Kung babalikan natin ang pamamaraan ng pagsusuri ni Demeterio, mapapansin natin ang sintetikong (synthetic) karakter nito: ang historyograpiya ni Salazar at ang teoryang demokratiko ni Weber. Ito ay "sintetik"sa simpleng dahilan (at hinihiram ko dito ang ideya ni Immanuel Kant ng "synthetic judgment") na bumubuo ito ng panibagong kaalaman tungkol sa sistemang pulitikal ng Pilipinas. Mas tiyak kung sasabihin natin na ang kasangkapang konseptuwal na ibinahagi ni Weber ay nagbigay daan sa panibagong persepsyon o interpretasyon ng mga sinaunang modelo ng 


\section{ISANG REAKSYON}

pamumuno na ibinahagi naman ni Salazar. Ang kombinasyon na ito ay magbibigay daan sa ating historikal at konseptwal na pag-unawa sa ating kasalukuyang sitwasyon. Dahil binibigyan diin ni Demeterio ang kasaysayansa pakiwari ko'y nais nyang suriin ang sistemang politikal ng bansa na higit sa tradisyunal na pamamaraan ng esentiyalismo o metapisika. Sa ibang salita, nais nyang ipakita na maaari din nating punahin ang kahabag-habag nating pambansang kondisyon kahit na hindi tayo malimit na dumulog sa moralistang lenguahe. Ang ibig kong sabihin ay ang mga suliranin natin ay may basehan sa kasaysayan, na kung ating bibigyang pansin, mauunawaan natin na tayo'y naghihirap dahil sa mga desisyon na ginawa natin sa loob ng ating kasaysayan. Sa pagkakataon na ito, binibigyan tayo ni Weber ng alternatibong lenguahe na base sa normatibong (normative) istraktura ng lipunan. Ito rin, sa palagay ko, ang basehan ng historyograpiya ni Salazar. Sa makatuwid, ang sintetikong pagsusuri ni Demeterio ay nakabase sa normatibong kabuuan ng lipunan; sa ibang salita, ang lipunan, base sa normatibong perspektibo, ay nabubuo ng ating mga materyal o konkretong asal, pananalita, paniniwala, at gawain na karaniwan sa atin. Ito na nga siguro ang ibig sabihin ng binanggit ni Demeterio na "iskema" o "script at scenario" ng lipunan. Ang mahalang maintindihan natin ay ang normatibong pamumuna ng lipunan ay hindi hango sa abstraktong konsepto nito, pero hango mismo sa konkretong senaryo ng isang lipunan. Sa madaling salita, ang lipunan ay katulad ng entablado ng dulaan o teatro, kung ilalagay natin sa metaporikal na salita.

Masasabi din natin na ang pagsusuri ni Demeterio ay "genealogical" na katulad ng pamamaraan ni Michel Foucault; sapagkat naipakita sa papel nya ang simula o "genealogical basis" ng pagkasira ng orihinal na istraktura ng pamamalakad ng lipunan sa Pilipinas. Dagadag dito, naipakita din ang patolohikal/pathological na kondisyon ng kasalukuyang sistema ng gobyerno sa ating bansa. Napakaimportanteng nabanggit ang pagdating at pagsakop sa atin ng mga Espanyol at Amerikano, dahil minamarkan ang parte ng ating kasaysayan ang kanilang pagsakop na siya ding pagpasok natin sa "modernismong" pamumuhay. Ang genealogical na karakter ng papel ay binibigyan tayo ng masmalinaw na ideya kung bakit humantong tayo sa ating kinaroroonan. Ayon kay Demeterio, salungat ang kasalukuyang sistemang politikal ng bansa sa ideyang demokratiko hango kay Weber; ang kondisyon na ito ay mauunawaan natin kung babalikan natin ang ating kasaysayan.

Kahanga-hanga ang ginawang pagsusuri ni Demeterio, at ako'y natutuwa at lubos ang aking pasasalamat dahil binigyan nya ako ng pagkakataon na basahin ang kanyang papel at isulat ang aking abang reaksyon. Bilang pagtatapos, baka mainam na magbangit ako ng tatlong bagay na, sa tingin ko, ang pinakatampok ng diskurso natin ngayong umaga base sa papel ni Demeterio:

1) Ang paggamit ng kasangkapang teoretikal o konseptual na pragmatikong paraan sa kritikal na pagsusuri ng mga suliranin natin na sosyolohikal at politikal. Kaugnay dito ang ating 
pagsasamalay sa importansya ng kasaysayan sa pagpupuna ng kasalukuyang sitwasyon.

2) Ang pagsasamalay ng normatibong pagpupuna na mas-epektibo at realistikong pamamaraan sa pagsusuri ng lipunan.

3) Napapahon ang lecture ni Demeterio sa konteksto ng nalalapit na eleksyon. Ito ay ekpresyon at inskripyon ng kabiguan at pag-asa.

Maraming salamat po sa pakikinig, at magandang umaga muli!

Department of Philosophy, University of Santo Tomas, Philippines 